\title{
Addressing maternal and child health in post-conflict Afghanistan: the way forward
}

\author{
P.K. Singh, ${ }^{1}$ R.K. Rai ${ }^{2}$ and M. Alagarajan ${ }^{7}$
}

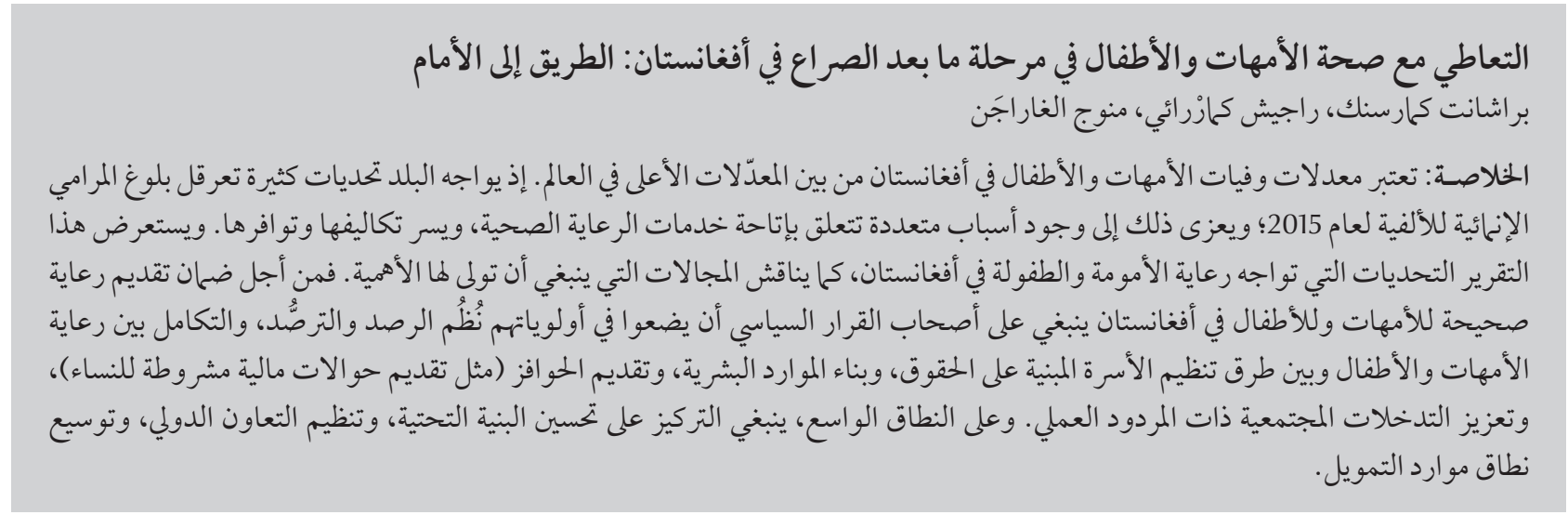

ABSTRACT Afghanistan's maternal and child mortality rates are among the highest in the world. The country faces challenges to meet the Millennium Development Goals set for 2015 which can be attributed to multiple causes related to accessibility, affordability and availability of health-care services. This report addresses the challenges in strengthening maternal and child health care in Afghanistan, as well discussing the areas to be prioritized. In order to ensure sound maternal and child health care in Afghanistan, policy-makers must prioritize monitoring and surveillance systems, integrating maternal and child health care with rights-based family planning methods, building human resources, offering incentives (such as the provision of a conditional cash transfer to women) and promoting action-oriented, community-based interventions. On a wider scale, the focus must be to improve the health infrastructure, organizing international collaboration and expanding sources of funding.

Prise en charge de la santé de la mère et de l'enfant en Afghanistan après les conflits : orientations futures

RÉSUMÉ Les taux de mortalité maternelle et infantile en Afghanistan comptent parmi les plus élevés au monde. Le pays est confronté à des défis pour réaliser les objectifs du Millénaire pour le développement fixés pour 2015. Les causes sont multiples, mais on peut citer l'accessibilité géographique et économique et la disponibilité des services de soins de santé. Le présent article traite des difficultés qui se posent en matière de renforcement des soins de santé maternelle et infantile en Afghanistan, et détaille les domaines à rendre prioritaires. Afin d'assurer des soins de santé de qualité aux femmes et aux enfants en Afghanistan, les décideurs politiques doivent accorder la priorité aux systèmes de surveillance et de suivi, en intégrant les soins de santé maternelle et infantile aux méthodes de planification familiale fondées sur les droits de l'homme, en renforçant les ressources humaines, en proposant des avantages (tels que des programmes de transfert conditionnel de fonds aux femmes) et en favorisant des interventions pratiques dans la communauté. À plus large échelle, l'accent doit être mis sur l'amélioration des infrastructures de santé, en organisant une collaboration internationale et en élargissant les sources de financement. 


\section{Background}

Afghanistan is the most dangerous place for a child to be born in Asia, according to a 2013 World Health Organization (WHO) and United Nations Children's Fund (UNICEF) joint report [1]. The long-term conflict in Afghanistan has adversely affected the health status of the population in general, and maternal and child health $(\mathrm{MCH})$ in particular. The situation is further confounded by barriers to access to health-care services [2]. Millions of people died during the 1992 civil war and the political unrest that followed still remains a serious concern [3]. The Afghan health care system, which was destroyed during the Taliban regime in 2001, has continued to suffer [4]. It is therefore not surprising that Afghanistan has some of the poorest $\mathrm{MCH}$ indicators worldwide. In the special edition of the State of the world's children report 2009, UNICEF expressed concern over Afghanistan's infant mortality rate, which is the highest in the world [5]. Furthermore, in the global mothers' index ranking, which includes 176 countries, Afghanistan was ranked 145 in the world in terms of mothers' well-being in 2013 [6].

According to the 2013 Human Development Report, Afghanistan was the 11th least developed country (ranked 175 out of 186 countries) in the world [7]. Additionally, if a child is fortunate enough to survive birth, the child could only expect to live for 44 years in Afghanistan, while the global life expectancy at birth is approximately 67 years for the period 2005-10. Recent estimates have confirmed that deaths from noncommunicable diseases are highest in Afghanistan [8]. While the new government, along with its international partners, has begun to rebuild the public health system since the Taliban regime ended in 2001, a great deal of work remains to be done in $\mathrm{MCH}$ care. This report aims to describe the current scenario, explain the present challenges in $\mathrm{MCH}$ care and suggest strategies that can ameliorate the situation.

\section{Maternal and child health: the current scenario}

Afghanistan is committed to the unprecedented global consensus Millennium Development Goals (MDG) of reducing the child mortality rate by two-thirds (MDG 4) and improving maternal health (MDG 5) by 2015, goals which present a great challenge to the Afghan health care system. Shortly after the establishment of the Transitional Islamic Republic of Afghanistan an interim national health policy and national health strategy were developed during 2002-04. Moreover, acknowledging the immediate response to poor health status of Afghani people, and addressing the country's worst health statistics, the Ministry of Public Health launched the basic package of health services (BPHS) in 2002 [9].

Despite some improvement in $\mathrm{MCH}$ indicators, the Maternal Mortality Estimation Inter-Agency Group have highlighted that the maternal mortality ratio (defined as the number of maternal deaths during a given time period per 100000 live births during the same time period) in Afghanistan was 460 per 100000 live births (95\% uncertainty interval: 250-850). This demonstrates insufficient progress towards achieving the Millennium Declaration [10]. The pregnancy-related mortality ratio is placed at 327 per 100000 (95\% uncertainty interval: 260-394); while in rural areas it is 417 (95\% uncertainty interval: 325-510), over 4 times that in the urban areas at 95 (95\% uncertainty interval: 54-135) [11]). Further, the lifetime risk of maternal mortality in Afghanistan is 1 in 32 [10].

Haemorrhage, which is by far the leading cause of maternal death in the majority of developing countries, was reported to be the major cause of maternal death in Afghanistan as well [12], followed by eclampsia and prolonged or obstructed labour [11]. Although over three-fifths of women in Afghanistan utilize some form of antenatal care services from skilled providers, only $16 \%$ met the World Health Organization (WHO) recommendation of at least 4 antenatal care visits. The latest estimates show that just 34\% of women had their birth attended by skilled birth attendants in a health facility, and nearly $75 \%$ of women had not received any postnatal checkups following delivery [11].

Currently, just 1 in 5 women in Afghanistan use any form of contraceptive, and this rate was even lower (1 in 10) among women in the age group 15-19 years. The adolescent birth rate, expressed as the number of births among girls aged $15-19$ years per 1000 girls is 151 , among the highest globally [13]. Age at marriage reliably predicts childbearing practices and the status of women in a given society [14]. In Afghanistan, approximately 21\% of women aged 25-49 years are married by age of 15 years and over 33\% of women have had their first birth by age 19 years, raising concerns about maternal and child morbidity as well as mortality at an early age [11]. Inequality in service utilization is also a major concern, as just $25 \%$ of women in rural areas utilized institutional delivery compared with over three-fifths of women from urban areas. Similarly, utilization of delivery care amongst the richest Afghan women is 6 times higher that of the poorest women [11].

From 1990 to 2011, Afghanistan's mortality rate for children under 5 years decreased from 192 to 101 deaths per 1000 live births [1]. This represents an average annual rate of reduction of 3.1 , suggesting only marginal progress. However, Afghanistan is one of the top 10 countries with the most under-5 deaths. Despite the overall reduction in under-5 mortality rates from 1990 to 2011 , the absolute number of under-5 
deaths has increased from 117000 in 1990 to 128000 in 2011 [1]. About half of under-5 deaths in Afghanistan are due to acute respiratory infections, followed by severe infections (20\%), prenatalrelated disorders (15\%), injury (9\%) and diarrhoea (6\%) [11]. In 2006, barely $27 \%$ of the children were fully immunized before their second birthday [15]. Chronic malnutrition (32\%) is also very high for children under 5 years old [13].

\section{Challenges and recommendations}

Since 2001, MCH status in Afghanistan has been improving slowly due to humanitarian efforts by several international agencies, but much remains to be done. Given that Afghanistan has the poorest $\mathrm{MCH}$ indicators in the world, coupled with a post-conflict environment and widespread poverty, a comprehensive action-based approach is needed in order to achieve the $\mathrm{MCH}$ targets of the MDG. Policy-makers must work towards an accessible, effective and sustainable $\mathrm{MCH}$ care system in Afghanistan, despite the numerous challenges that are present.

\section{Need to strengthen $\mathrm{MCH}$ information and monitoring/ surveillance system}

Minimizing the $\mathrm{MCH}$ knowledge gap is an essential component for effective programme and policy implementation, particularly in post-conflict nations such as Afghanistan [16]. Low levels of knowledge about MCH care, characterized by incomplete and/or contradictory data, could divert the entire resource allocation pattern, as witnessed in the Congo [17]. In the case of Congo, the World Bank emphasized the need to examine health-care delivery systems developed during the conflict [17]. In addition, establishment of proper monitoring and surveillance systems is crucial to assess the coverage of ongoing programmatic efforts.
For instance, after 2001, the Afghan Ministry of Public Health has launched several programmes and interventions including the BPHS; however the actual extent of these services coverage remains unclear [18]. Previous studies have confirmed that there is a lack of standardized national system for ensuring quality during the delivery of the BPHS in Afghanistan and it varies across regions and providers. Thus, a proper monitoring system may ensure standard practices and encourage providers to pursue standardized norms for service delivery. It also helps to understand the magnitude and nature of huddles that restricts the coverage of $\mathrm{MCH}$ care services.

\section{Importance of databases for planning and evaluation}

To reach the maximum population in need of essential MCH care services, particularly those who are uneducated, poor and residing in remote places, the importance of timely and adequate database management for better planning and evaluation should not be ignored. It is essential, since the distribution of health services in any country is based on demand and supply side factors. Thus, an independent $\mathrm{MCH}$ analysis unit established under the Ministry of Public Health in Afghanistan could examine different sources of data/information and how to integrate them with a wider health system.

\section{Integrating family planning and $\mathrm{MCH}$ care}

The high total fertility rate of 5 births per woman, leading to rapid population increases, coupled with a low rate of contraceptive use, could adversely affect the efforts to improve health, education and employment. An important way to confront population growth and spur economic development is through the provision of integrating rights-based family planning (FP) and $\mathrm{MCH}$ care [19]. This approach is recognized as a cost-effective way to prevent unintended pregnancies, reduce maternal and child mortality and improve the overall $\mathrm{MCH}$ status [20]. Integrating $\mathrm{FP}$ and $\mathrm{MCH}$ services typically means offering women a broad set of $\mathrm{FP}$ and $\mathrm{MCH}$ services during the same appointment, at the same service delivery site, from the same service provider [21]. In addition, effective consultations about specific $\mathrm{MCH}$ needs should be provided to women during their first antenatal care visit, in order to ensure subsequent service utilization. What are proper $\mathrm{MCH}$ care practices and how to implement them should be explained in detail. For countries with established traditions of administering $\mathrm{FP}$ and $\mathrm{MCH}$ programmes separately, integration of the 2 priority areas may be met with resistance [21]. However, since Afghanistan is in the initial stage of establishing its health-care system, it has the unique advantage of being able to introduce a system that integrates FP and $\mathrm{MCH}$ effectively.

\section{Recognizing $\mathrm{MCH}$ needs as a human right and as a means to achieve the MDGs}

Accessing health care represents a unique challenge for Afghan women. The social system in Afghanistan is strongly patriarchal and men largely control women's mobility [4]. Access to education and health care remains poor, while forced marriage and domestic violence are experienced by a large percentage of Afghan women [14]. This oppressive environment has a profound impact on women's self-confidence, self-esteem and ability to take control of their lives and engage in public affairs. Nearly 1 in 5 women reported that they did not get permission to utilize ANC and safe delivery care [11]. The process of creating a safe environment that will encourage women to seek health care, education and other economic opportunities must be initiated at the family and societal level. Promoting higher education for women is perhaps the best possible way to promote rights-based 
interventions for health care utilization. Education of girls should be the new government's primary goal. There should also be provision for re-enrolment for women and girls who have dropped out of school. In addition, promotion of distance learning could be an effective way to reach remote areas as it does not require students to be physically present, allowing for a flexible educational environment alongside regular housework. Educational curricula should promote health awareness, including knowledge of common diseases and how to prevent them. Educational courses in conflict resolution could perhaps contribute to a calm and safe home environment, as well as improved negotiation skills for women and girls.

\section{Improving human resources for health}

Shortage of health-care workers poses a major challenge for Afghanistan's health care system. There are only 6000 physicians and 14000 nurses serving a population of 28 million people [22]. Female providers currently constitute only $24 \%$ of the workforce, with considerable variations across provinces [22]. Another obstacle is the lack of qualified health-care workers. About 70\% of the nurses, midwives and laboratory technicians do not meet minimum knowledge and skills standards. Further, for various reasons, health-care workers prefer to work in urban areas [23]. There is a need for a comprehensive policy on human resources for health, which ensures planning the national health workforce, estimating the size and composition of the future workforce, defining the roles of health workers, developing standardized training programmes and minimum staffing standards for health facilities at different levels. In addition, developing undergraduate public health degree programmes and evaluating the performance of health workers on a periodic basis will ensure a trained pool of public health professionals. A collaborative approach between the
Ministry of Public Health and Ministry of Higher Education, recognizing both workforce requirements and educational standards, is perhaps the best approach for meeting the need for skilled human resources for obstetric care [24].

\section{Addressing poverty and health gaps in $\mathrm{MCH}$}

Socioeconomic and regional inequality in health services utilization is a major global concern and Afghanistan is no exception. The Afghanistan mortality survey, conducted in 2010, revealed huge socioeconomic and regional inequalities in $\mathrm{MCH}[11]$. The rates of safe delivery in urban areas were more than twice that in rural areas (66\% and 25\% respectively). Similarly, safe delivery care was about 6 times higher among women belonging to the highest wealth quintile (63\%) compared with the lowest (11\%). The under-5 mortality rate was higher among the most remote quintile (93 per 1000 births) compared to the least remote quintile (69 per 1000 births). Recent estimates confirm that more than half of Afghan women reported lack of money as a reason for not delivering in a health facility and this figure is as high as 70\% among women from the poorest wealth quintile [11]. Similarly, children born to mothers in the highest wealth quintile have half the risk of mortality compared with those born to mothers in the poorest wealth quintile (49 and 106 per 1000 live births respectively). The issue of poverty as a barrier to obtaining MCH could perhaps be addressed by introducing a financial mechanism, such as a voucher or conditional cash transfer. This voucher system, which has been adopted by several countries, could be used to provide services and transportation to facilities free of charge or at a highly subsidised rate, which may increase the utilization of health services [25].

\section{Providing basic infrastructure and ensuring quality of care}

The lack of basic infrastructure in the country adversely affects the health care system, as only $6 \%$ of Afghans have access to reliable electricity sources and just 30\% of rural households have access to safe drinking water [22]. The extreme climate and terrain combined with the lack of roads in many parts of Afghanistan makes it difficult to access health facilities. Effective and efficient health-care systems require investment in transportation, electricity, safe water and hygiene and communication, particularly in rural areas and remote regions. Ensuring quality of care in $\mathrm{MCH}$ must be prioritized. The Afghanistan mortality survey found that a substantial proportion (35\%) of women had not utilized maternity services due to quality-related issues that included poor service quality, inconvenient service hours, long waiting periods and lack of female providers [11]. A recent study in Afghanistan observed that the quality of care in provincial hospitals fell below the Integrated Management of Childhood Illness standards [26], and presented a compelling reason to include such training standards developed by $\mathrm{WHO}$ and UNICEF [27]. Improving communication between health professionals and pregnant women could also raise women's confidence with respect to the utilization of health facilities.

\section{Encouraging family and community support/ participation in $\mathrm{MCH}$}

Family and community support for women during pregnancy and childbirth must be a key component of safe motherhood programmes. In this regard, midwives and local nongovernmental organizations (NGOs) could play a vital role in disseminating health promotion at the family and community levels. Additionally, the effect of traditional cultural health practices among several tribes (such as the Turkmen, Uzbek, Baloch, Pashai who are geographically isolated) and of religious beliefs should not be overlooked by ongoing health programme efforts. Evidence from South Asian countries, 
including India [28], Pakistan [29] and Bangladesh [30] suggests that religion is an important predictor of demographic and health outcomes. Further, certain norms and characteristics of some ethnic groups may encourage negative attitudes toward modern medicines and health service utilization. Studies have shown that collaboration between religious leaders and health officials are vital for changes in health and risky behaviour [31]. In order to enhance family and community level efforts, cultural and religious misconceptions regarding health care must be addressed. Targeting senior males (including husbands) and females of households, along with other influential community stakeholders (including religious leaders) are essential aspects of communication activities for behaviour change. In addition, women advocacy groups and self-help groups at the village level could serve as effective communication tools in spreading awareness about the importance of timely and proper $\mathrm{MCH}$ care.

\section{Political commitment and willingness in $\mathrm{MCH}$}

The importance of strong political commitment to encourage good health was highlighted first by Rosenfield in 1985 [32] and put politics firmly on the map as an important explanatory factor of good health in low-income countries. The significance of political commitment in health was also highlighted by the WHO Commission on Social Determinants of Health, which stated that poor health was not a natural state of affairs but the result of "a toxic combination of poor social policies and programmes, unfair economic arrangements, and bad politics" [33]. Although the evidence supporting political commitment as a key to good health has not been compelling, experiences from some South and East Asian countries such as Bangladesh, Sri Lanka, Thailand and other countries such as Ethiopia have shown that strong political commitment profoundly strengthens the performance of the health-system even in poor resource settings. Experiences from these countries can help Afghan political establishment to optimize the efforts in support with experiences from international agencies working in Afghanistan to ensure a higher reach of essential MCH services.

\section{Other issues}

Although Afghanistan has been supported by several international donors, it is uncertain whether the support will be continued, given the persistent economic hardship in donor countries [27]. In the case of post-conflict nations such as Afghanistan, continued funding for health system development is essential. Along with financial support, there is need for national/international interagency coordination. An effective and efficient coordination mechanism between different agencies requires the generation of more robust information in order to create a sustainable, nationwide health care system. In Afghanistan, nearly $70 \%$ ofmedical programmes have been implemented by aid organizations [34], and medical services have been provided mostly by NGOs contracted through the Ministry of Public Health [8]. In Afghanistan, contracting with NGOs has proved to be a way for the government to gain and maintain policy leadership [35]. However, there are no guidelines or mechanisms to encourage international NGOs to build the capacity of local NGOs [18]. By setting priorities, establishing the division of responsibility, providing financing and monitoring, NGOs could be given a fair degree of autonomy while still being held accountable for achieving national goals. This could be one of the key issues in reorienting the health delivery system in the country [36]. Ensuring a safe and secure environment for health-care providers and those trying to seek health care, particularly women, is one of the greatest challenges for the new government. Approximately $12 \%$ of women reported security reasons for not utilizing maternity services and this figure was as high as 30\% in the eastern and south eastern regions of Afghanistan [11]. In 2007, about $45 \%$ of Afghanistan's districts were inaccessible to United Nations missions for extended periods of time due to security constraints and movement restrictions [37]. The security conditions have worsened in certain parts of Afghanistan, including the southern region, where the latest mortality survey was not conducted owning to security reasons.

\section{Conclusion}

Afghanistan has a long way to go in achieving acceptable standards of $\mathrm{MCH}$ care. However, there are several opportunities that must be considered in deciding how to pace development efforts. There is a need to capitalize on the opportunity for the Afghan government's work with international partners such as the United States Agency for International Development, WHO, the World Bank, UNICEF and the European Union. These organizations provide valuable knowledge and experience that can be effectively used towards building a sustainable health care system in Afghanistan. In addition, learning from the successes and failures of other post-conflict countries such as the Congo, Haiti and Sudan could facilitate improved MCH care.

Health policies must focus on strategies that reach the poor and those in underserved regions. This calls for sufficient willing and well-trained healthcare workers. With the help of local NGOs, midwives and other stakeholders, families and communities can be mobilized to improve $\mathrm{MCH}$ care by creating awareness through effective communication strategies, and providing information about the benefits of proper and timely utilization of $\mathrm{MCH}$ services. An essential component of any long-term safe motherhood programme is to educate and empower women at the 
community level. This will increase their economic opportunities and overall willingness to seek maternal health-care services. The long-term goal of improving $\mathrm{MCH}$ care in Afghanistan can be met only through a combination of a specific action-based approach, foreign aid and domestic accountability.

Competing interests: None declared.

\section{References}

1. Accountability for maternal, newborn and child survival: the 2013 update. Geneva, World Health Organization/United Nations Children's Fund, 2013.

2. Reilley B, Puertas G, Coutin AS. The battle for access-health care in Afghanistan. New England Journal of Medicine, 2004, 350:1927-1929.

3. Bohannon J. The war in Afghanistan. Counting the dead in Afghanistan. Science, 2011, 331:1256-1260.

4. Hirose A et al. Difficulties leaving home: a cross-sectional study of delays in seeking emergency obstetric care in Herat, Afghanistan. Social Science and Medicine, 2011, 73:1003-1013.

5. The state of the world's children 2009: maternal and newborn health. New York, United Nations Children's Fund, 2009.

6. Surviving the first day: state of the world's mothers 2013. Westport, Connecticut, Save the Children, 2013.

7. Human development report 2013. The rise of south: human progress in a diverse world. New York, United Nations Development Programme, 2013.

8. Zarocostas J. Deaths from non-communicable diseases are highest in Afghanistan, lowest in Sweden. British Medical Journal, 2011, 343:d5876.

9. A basic package of health services for Afghanistan 2005/1384. Kabul, Afghanistan, Ministry of Public Health, 2005.

10. Trends in maternal mortality: 1990 to 2010. Geneva, World Health Organization/ United Nations Children's Fund/United Nations Population Fund/The World Bank, 2012.

11. Afghanistan mortality survey 2010. Calverton, Maryland, Macro for Public Health Institute, Afghan Ministry of Public Health/ Central Statistics Organization (Afghanistan)/Indian Institute of Health Management Research/World Health Organization Regional Office for the Eastern Mediterranean, 2011.

12. Bartlett LA et al.; Afghan Maternal Mortality Study Team. Where giving birth is a forecast of death: maternal mortality in four districts of Afghanistan, 1999-2002. Lancet, 2005, 365:864-870.

13. World health statistics 2017. Geneva, World Health Organization, 2011.

14. Raj A, Gomez CS, Silverman JG. Multisectorial Afghan perspectives on girl child marriage: foundations for change do exist in Afghanistan. Violence Against Women, 2011, doi: 10.1177/1077801211403288.

15. Johns Hopkins University Bloomberg School of Public Health, Indian Institute of Health Management Research. Afghanistan health survey 2006: estimates of priority health indicators. Kabul, Afghanistan, Ministry of Public Health, 2008.

16. Smith JM, Burnham G. Conceiving and dying in Afghanistan. Lancet, 2005, 365:827-828.

17. The Inspection Panel Report and Recommendation on Request for Inspection-Democratic Republic of Congo: transitional support for economic recovery credit operation and emergency economic and social reunification support project. Washington DC, World Bank, 2006.

18. Sabri B et al. Towards sustainable delivery of health services in Afghanistan: options for the future. Bulletin of the World Health Organization, 2007, 85:712-718.

19. Cecatti JG et al. The associations between inter-pregnancy interval and maternal and neonatal outcomes in Brazil. Maternal and Child Health Journal, 2008, 12:275-281.
20. Headey D, Hodge A. The effect of population growth on economic growth: a meta-regression analysis of the macroeconomic literature. Population and Development Review, 2009, 35:221-228.

21. Waddington C, Egger D. Integrated health services-what and why? Geneva: World Health Organization, 2008.

22. Global Health Observatory: Country profile, Afghanistan. World Health Organization (http://www.who.int/gho/countries/ afg/country_profiles/en/index.html, accessed 8 June 2013).

23. Country cooperation strategy for WHO and Afghanistan, 20062013. Cairo, World Health Organization Regional Office for the Eastern Mediterranean, 2010 (EM/ARD/043/E).

24. Mansoor GF, Hill PS, Barss P. Midwifery training in post-conflict Afghanistan: tensions between educational standards and rural community needs. Health Policy and Planning, 2012, 27:60-68.

25. Fiszbein A, Schady N. Conditional cash transfers: a World Bank policy research report. Washington DC, World Bank, 2009.

26. Lind A et al. Quality of outpatient hospital care for children under 5 years in Afghanistan. International Journal for Quality in Health Care, 2011, 23:108-116.

27. Armstrong Schellenberg JR et al. Effectiveness and cost of facility-based integrated management of childhood illness (IMCI) in Tanzania. Lancet, 2004, 364:1583-1594.

28. Singh PK et al. Determinants of maternity care services utilization among married adolescents in rural India. PLOS ONE, 2012, 7:e31666.

29. Nasir JA, Hinde A. Factors associated with contraceptive approval among religious leaders in Pakistan. Journal of Biosocial Science, 2011, 43:587-596.

30. Miah MMR. The cultural-structural contexts of high fertility in Bangladesh: A sociological analysis. International Review of Modern Sociology, 1992, 22:99-110.

31. Islamic Medical Association of Uganda. AIDS education through Imams. A spiritually motivated effort in Uganda. UNAIDS case study. Geneva, Joint United Nations Programme on HIV/AIDS, 1998.

32. Rosenfield P. Social and political factors. In: Halsted SB, Walsh JA, Warren KS, eds. Good health at low cost: proceedings of a conference held at the Bellagio Conference Centre. New York, Rockefeller Foundation, 1985:173-180.

33. Commission on Social Determinants of Health. Closing the gap in a generation: health equity through action on the social determinants of health. Geneva, World Health Organization, 2008.

34. Leach-Kemon $\mathrm{K}$ et al. The global financial crisis has led to a slowdown in growth of funding to improve health in many developing countries. Health Affairs, 2012, 31:228-235.

35. Yusufzai A. Poor medical facilities in Afghanistan mean patients turn to hospitals in Pakistan. British Medical Journal, 2008, 337:a2291.

36. Loevinsohn B, Sayed GD. Lessons from the health sector in Afghanistan: how progress can be made in challenging circumstances. Journal of the American Medical Association, 2008, 300:724-726.

37. Funding appeals and humanitarian action updates. United Nations Children's Fund [online] (http://www.unicef.org/ infobycountry/afghanistan_31224.html, accessed 8 June 2013). 